\title{
Modeling of factors influencing exploration of medical career
} choices

\author{
Rizma Adlia Syakurah ${ }^{1}$, Yayi Suryo Prabandari², Widyandana ${ }^{3}$, Taufan Bramantoro ${ }^{4}$ \\ ${ }^{1}$ Faculty of Public Health, Universitas Sriwijaya, Indonesia \\ ${ }^{2}$ Department of Health Behaviour, Environment Health, and Social Medicine, Faculty of Medicine, Public Health and \\ Nursing, Universitas Gadjah Mada, Indonesia \\ ${ }^{3}$ Department of Medical Education, Faculty of Medicine, Public Health and Nursing, Universitas Gadjah Mada, Indonesia \\ ${ }^{4}$ Department of Dental Public Health, Faculty of Dental Medicine, Universitas Airlangga, Indonesia
}

\begin{tabular}{|c|c|}
\hline Article Info & ABSTRACT \\
\hline $\begin{array}{l}\text { Article history: } \\
\text { Received Jun 9, } 2020 \\
\text { Revised Dec 20, } 2020 \\
\text { Accepted Jan 3, } 2021\end{array}$ & $\begin{array}{l}\text { Majority of medical students choose clinical specialties as their career } \\
\text { choice, compared to other medical fields. This study aimed to finding an } \\
\text { effective model of career exploration behaviour in medical students to } \\
\text { construct effective career interventions. This study obtained } 1030 \text { students of } \\
\text { medical faculties in Indonesia. All data used an online survey questionnaire } \\
\text { that was collected starting from October } 12^{\text {th }}-25^{\text {th }} 2015 \text {. Data analysis used }\end{array}$ \\
\hline $\begin{array}{l}\text { Keywords: } \\
\text { Career choice } \\
\text { Medical career } \\
\text { Medical education } \\
\text { Self-efficacy } \\
\text { Undergraduate }\end{array}$ & $\begin{array}{l}\text { Partial Least Square-Path Modelling using } \mathrm{R} \text { statistical software to create a } \\
\text { model in order to find correlation and pathway among each variable. The } \\
\text { result showed both direct and indirect correlation towards the variables } \\
\text { studied. Personal accomplishment had a stronger influence on self-efficacy } \\
(\beta=0.317, p<0.001) \text {. This study concluded that verbal persuasion and self- } \\
\text { efficacy correlate directly to career exploration. All variables are related to } \\
\text { career exploration in medical students. Educators and policymakers are able } \\
\text { to construct intervention in this area to encourage medical students to start } \\
\text { exploring career options early. }\end{array}$ \\
\hline
\end{tabular}

This is an open access article under the CC BY-SA license.

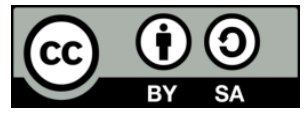

\section{Corresponding Author:}

Rizma Adlia Syakurah

Faculty of Public Health

Universitas Sriwijaya

Jl. Raya Palembang-Prabumulih KM. 32 Indralaya, Ogan Ilir, South Sumatra, 30662, Indonesia

Email: rizma.syakurah@gmail.com

\section{INTRODUCTION}

Careers in medicine are generally divided into two areas, namely the clinical and non-clinical careers. Clinical fields include general practitioners, family physicians, specialists, consultants, etc. Nonclinical fields include anatomy, physiology, histology, molecular biology, epidemiology, health economics, community medicine, medical education, etc [1]. Moreover, more physicians started to explore non-medical careers as well [2]. Majority of medical students around the world choose clinical specialties as their career choice, compared to other medical fields. It's based on various reasons and considerations in themselves, the environment around them and career opportunities [3-5].

Based on the fact that the majority of medical students preferred to choose clinical careers especially in Indonesia, it is hard to find professionals based on non-clinical fields. Various cases in developed countries shows that the low interest in the field of non-clinical also supported by their concerns about income, curriculum lead faculty do not have the time to introduce and develop the interest of students, their policies 
relating to the registration of doctors who make it difficult for them to focus on research [6, 7]. To get a balanced distribution of professions between clinical and non-clinical fields, medical students need to start exploring their career choices early, in the hope they do not only choose clinical careers as their career choice. Medical students can choose hundreds of medical careers that suit their preferences, personal values, and abilities. Finding career choices can help students to plan their college life accordingly. Various theories and researches emphasized the importance of self-efficacy on career choice [8]. Hence, sources of selfefficacy are also considered vital in constructing an individual career-related behavior [8-11]. Self-efficacy (beliefs about one's ability to perform), outcome expectations (contingency beliefs that someone's efforts will result in consequences they desired), and goals/intentions, are directly influence career action, such as career planning and career exploration that are important elements in career decision-making [10].

Finding an effective model for career exploration behavior in medical students is important in order to provide them with the most effective method to enhance medical students' ability and desire to choose a suitable career path. The model product from this research is expected to help many medical students in choosing various types of medical careers. This model will provide an effective suggestion for counselling medical students in career choices and hopefully contribute to the equitable distribution of medical professions in Indonesia.

\section{RESEARCH METHOD}

A cross sectional design was used in this study. The population of this study was medical students from all 85 medical faculties in Indonesia. Participants were voluntary and did not receive incentives to participate in this study. Questionnaires submitted online through the Google Form application starting from October 12th-25th 2015 were delivered via emails to students' representatives of every medical faculty, with a total response of 1030 participants from 67 universities obtained by accidental sampling. The minimum sample size is determined based on the sample size formula for the average difference hypothesis in the two independent groups which results in a minimum sample size of 1001. This research had been deemed ethically feasible from the research-ethics commission of Medical Faculty of Sriwijaya University and RSUP Mohammad Hoesin Palembang, number No.398/KEPKRSMHFKUNSRI/2015.

The questionnaire used close-ended questions with Likert scale which have been translated and validated from the career decision making self-efficacy scale-short form (CDSME-SF) to measure selfefficacy, the career exploration survey-revised (CES-R) to measure career exploration, the Career Decisionmaking outcome expectations (CDMOE) to measure career outcome expectation, and the career exploratory plans or intentions (CEPI) to measure career exploration intention [9, 11-13]. The questionnaire validity test was done by Pearson Product Moment (r). The Alpha-Cronbach results on CSESS, CDMSE-SF, CES-R, CDMOE, and CEPI were 0,935, 0.912, 0.803, and 0.737 .

The obtained data in this study was processed based on the results of the questionnaire. After the data were collected, statistical analysis and interpretation of data were performed using Mann-Whitney and Chi-square test $(\mathrm{p}<0.05)$ to compare characteristic respondents and career choice. While, Partial Least Square-Path Modelling using R statistical software to create a model in order to find correlation and pathway among each variable.

\section{RESULTS AND DISCUSSION}

From 1030 samples, 685 samples $(66.5 \%)$ were females and $345(33.5 \%)$ were males. In career choice question, most of the students choose to be specialists, with 657 responses $(63.8 \%)$. Table 1 displays the characteristic of participants and a bivariate correlation between socio-demographic. Age, marital status and current educational status were statistically related to career choices as shown in Table 1 .

All hypothesized pathways are explained, with path coefficient or $\beta$ values indicating the effect direction and magnitude of relationship as shown in Table 2. In this model, there were significant direct pathways: (a) Personal accomplishment to self-efficacy $(\beta=.317, p<.001)$; (b) Emotional arousal positive to self-efficacy $(\beta=.161, p<.001)$; (c) Emotional arousal negative to self-efficacy $(\beta=-.139, p<.05)$; (d) Verbal persuasion to self-efficacy $(\beta=.129, \mathrm{p}<.05)$; (e) Self-efficacy to outcome expectations $(\beta=.229, \mathrm{p}<.001)$; (f) Self efficacy to career intentions $(\beta=.257, \mathrm{p}<.001)$; (g) Self efficacy to career exploration $(\beta=.446, \mathrm{p}<.001)$; (h) Outcome expectation to career intentions $(\beta=.422, \mathrm{p}<.001)$; (i) Career intentions to Career exploration $(\beta=.080, \mathrm{p}<.001)$. Regarding the direct pathways of career exploration, self-efficacy had the highest path coefficient. The model accounted for $40 \%$ of the variance in self-efficacy, $13 \%$ in outcome expectations, $34,6 \%$ in career intentions, and 52,5\% in career exploration. 
Marital status and current educational status are both influenced by age, as Indonesian regulation has a restriction on marriage and university admission age. Age as a determinant in a career choice is in accordance with previous career-related researches and theories [3, 14-16].

Table 1. Characteristics of participants

\begin{tabular}{|c|c|c|c|}
\hline Variable & Frequency & Percentage (\%) & $\mathrm{p}$-value \\
\hline \multicolumn{4}{|l|}{ Age } \\
\hline Mean & 21.29 & & \multirow{5}{*}{$<0.001$} \\
\hline Median & 21.35 & & \\
\hline SD & 2.10 & - & \\
\hline Maximum & 29 & & \\
\hline Minimum & 16 & & \\
\hline \multicolumn{4}{|l|}{ Gender } \\
\hline Male & 345 & 33.5 & \multirow{2}{*}{0.451} \\
\hline Female & 685 & 66.5 & \\
\hline \multicolumn{4}{|l|}{ Marital status } \\
\hline Married & 1003 & 97.4 & \multirow{2}{*}{0.007} \\
\hline Unmarried & 27 & 2.6 & \\
\hline \multicolumn{4}{|l|}{ University of origin } \\
\hline State & 697 & 67.7 & \multirow{2}{*}{0.096} \\
\hline Private & 333 & 32.3 & \\
\hline \multicolumn{4}{|l|}{ Current education status } \\
\hline Fresh graduate & 149 & 14.5 & \multirow{3}{*}{$<0.001$} \\
\hline Clinical clerkship & 305 & 29.6 & \\
\hline Preclinical students & 567 & 55.9 & \\
\hline \multicolumn{4}{|l|}{ Career choice } \\
\hline Specialists & 657 & 63.8 & \\
\hline Non-specialists & 97 & 9.4 & - \\
\hline Undecided & 276 & 26.8 & \\
\hline Total & 1030 & 100.0 & - \\
\hline
\end{tabular}

Table 2. Summary data and path coefficient correlation, $n=1030$

\begin{tabular}{lcccccc}
\hline \multicolumn{1}{c}{ Variables } & Mean & SD & Self-efficacy & Outcome expectations & Career intentions & Career exploration \\
\hline Vicarious learning & 3.404 & 0.422 & 0.098 & 0.205 & 0.159 & 0.145 \\
Personal accomplishment & 3.438 & 0.626 & $0.317^{\mathrm{c})}$ & -0.091 & -0.07 & 0.079 \\
Emotional arousal positive & 3.564 & 0.564 & $0.161^{\mathrm{c}}$ & 0.0386 & -0.055 & 0.027 \\
Emotional arousal negative & 2.834 & 0.913 & $-0.13^{\mathrm{a}}$ & -0.008 & -0.043 & 0.057 \\
Verbal persuasion & 3.528 & 0.716 & $0.129^{\mathrm{a})}$ & 0.032 & 0.015 & $0.128^{\mathrm{a})}$ \\
Self-efficacy & 3.629 & 0.650 & - & $0.229^{\mathrm{c})}$ & $0.257^{\mathrm{c})}$ & $0.446^{\mathrm{c})}$ \\
Outcome expectations & 4.024 & 0.525 & & - & $0.422^{\mathrm{c})}$ & -0.028 \\
Career intentions & 4.187 & 0.609 & & & - & $\left.0.080^{\mathrm{c}}\right)$ \\
Career exploration & 3.235 & 0.672 & & & & - \\
\hline Significance level of $\left..05{ }^{\text {a) }} \mathrm{p}<0.05 ;{ }^{\mathrm{b})} \mathrm{p}<0.01 ;{ }^{\mathrm{c})} \mathrm{p}<0.001\right)$ & & &
\end{tabular}

The youngest group of samples in this study was sixteen years old, which was currently still on their early stage of career exploration during their crystallization phase of career task [16]. On this phase of career development, someone started to experience and explore possible careers for them in order to narrow their choices and start to develop tentative vocation goals. Mean age of the samples twenty-one years old, was categorized to be in the later phase of the career exploration stage. During this phase, their choices and goals are being made and they started to act on their plan, such as going to a certain workshop related to their preferred career. These career tasks are called specification and implementing. After they finished their exploration stage, they will start to choose, adapt, and determine their preferred career $[16,17,18]$.

In this study, we found that sex did not influence medical career choices as theories and previous researches $[3,8,19-21]$. There are more ways to explain how the result was different to previous theories and researches in career choices. Aside of gender belief and stereotypes on what considered as appropriate career choices for a certain sex, the high amount of female medical students and physicians as role models in the medical field slowly makes career choices in medical to be more equal [22-24]. Moreover, previous research on similar demographic shown that sex has weak correlations with career aspirations, planning, and exploration $[3,25]$.

However, there were non-significant direct pathways. Vicarious learning had no significant direct effect on self-efficacy, outcome expectations, career intentions, and career exploration. No significant direct effect was found in personal accomplishment, positive emotional arousal, and negative emotional arousal to outcome expectations, career intentions, and career exploration, respectively. Verbal Persuasion had no 
significant direct effect on outcome expectation and career intentions. Moreover, outcome expectations had no significant direct effect on career exploration. Furthermore, in regards to indirect link pathways of career exploration, there were several significant indirect effect to career exploration: (a) Personal accomplishment (via self-efficacy, CIs=0.22 to 0.43); (b) Positive emotional arousal (via self-efficacy, CIs=0.03 to 0.28); (c) Negative emotional arousal (via self-efficacy, CIs $=-0.26$ to -0.01 ); (d) Verbal persuasion (via self-efficacy, CIs $=0.01$ to 0.24 ); (e) Self efficacy (via career intention, CIs=0.28 to 0.43 ). All the results are made into a model with only significant paths included avoiding visual chaos as shown in Figure 1.

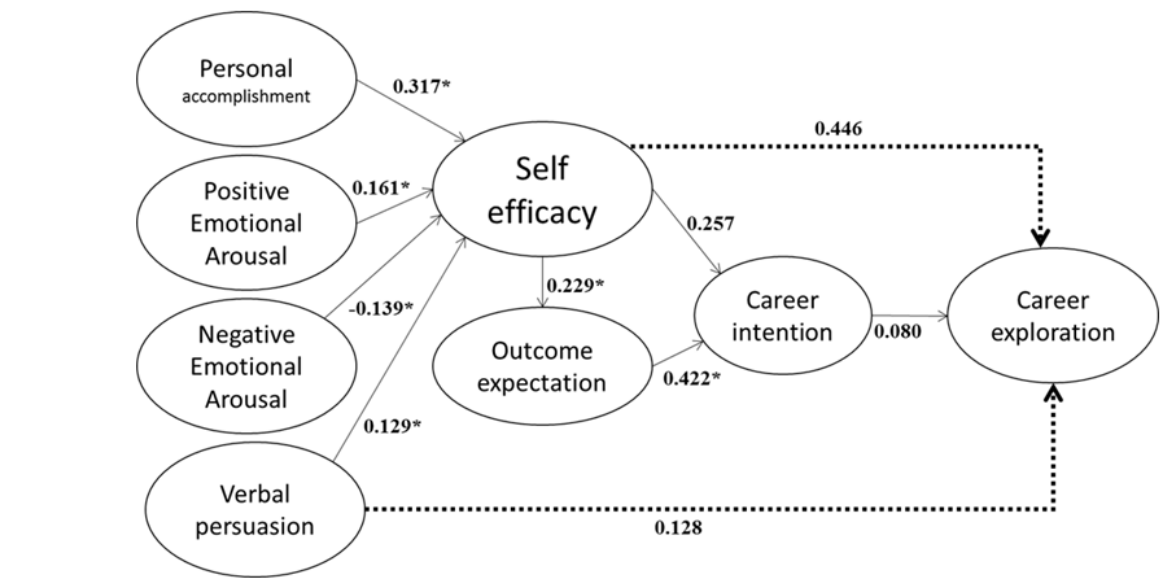

Full lines reflect to SCCT and Bandura model, dashed lines reflect direct additional relationships towards career exploration $* \mathrm{p}<0.05, * * \mathrm{p}<0.01, * * * \mathrm{p}<0.001$

Figure 1. The final model with only significant paths included to avoid visual clutter

Three of sources of self-efficacy, personal accomplishment, positive emotional arousal, and verbal persuasion, had a positive relationship to self-efficacy, while negative emotional arousal had a negative relationship to self-efficacy. The strongest predictor of self-efficacy was a personal accomplishment, as it was supported in previous researches [11, 26]. High self-efficacy beliefs from past experiences of achievement and mastery will influence individuals to think positively about their future career path. Emotional arousal, whether it was on a positive or negative state, had its influence on self-efficacy. People often rely on their emotion as an encouragement to help determine whether they will be successful at a certain task [26].

Verbal persuasion is also proven to be statistically influential to self-efficacy as it was shown in previous theories and researches $[11,25,26]$. One particular research in a similar cultural setting also shown that verbal persuasion affects career exploration although there is no significant influence in self-efficacy. It is assumed that parents expect their children to pursue occupations that are financially secure and rewarding and that are practical or more marketable [27]. An interesting finding in this study is the occurrence of direct influence from verbal persuasion to career exploration. In a collectivist culture as Indonesia, the act of exhortation and suggestion goes a long way, especially if the reinforcement comes from someone in higher hierarchy level, parents as examples [25, 28]. High power distance culture makes children value their seniors' suggestions and expectations, so much they are willing to compromise with their career path [25, 29]. In a collectivist culture, parents' expectations and suggestions are influential on important life decisions such as choosing a career. It is considered a joint decision instead of a personal decision [25]. So, children in the collectivist community, verbal persuasion can enhance not only personal self-efficacy but the act of career exploration.

Self-efficacy has a significant influence on outcome expectation, as supported by previous findings $[10,11]$. Outcome expectation, both academic and career ones, are needed in the career decision making process [13]. Having high outcome expectation in a medical career is consider given because generally public assumed that when someone entering profession career field, like medical or law, they will be practicing the field professionally, and independently [30]. Self-efficacy influence career intention directly, and indirectly through outcome expectation as mediator. Previous research has already shown that high self-efficacy will lead to an interest in developing themselves [9,11]. It applies to outcome expectation as well. Self-efficacy also shows a direct relationship to career exploration as supported by a previous study [11, 25]. 
In order to increase medical students' career exploration, high school and medical schools can support them with personal or family career counselling, in order to find common ground and decide together what will be the best for the student's interest [29]. Early exposure to a variety of careers will enhance students' awareness of their future options [31] while finding what they can do best in certain fields will increase their personal performances aiding in their career decisions. Faculty can accommodate these activities by making internship opportunities, courses or programs that will help students learn more about their possible choices [32]. Parents can also be more involved in these activities, so they can give rational guidance and personal persuasion to their children.

\section{CONCLUSION}

Based on the results and discussion of this research, it is concluded that contributable variables studied are related to career exploration in medical students, both directly and indirectly. Verbal persuasion and self-efficacy affect career exploration directly. Several activities can be done early in their program of study in order to increase medical students' career exploration and help them to find the career that is suitable for their personal values, interest, and ability. The findings demonstrate the importance of sources of selfefficacy in medical students' career exploration behavior. Educators and policymakers are able to construct intervention in this area to encourage medical students to start exploring career options early.

\section{ACKNOWLEDGEMENTS}

We wish to acknowledge our participants for their time and contributions toward this study. We also want to acknowledge Atika Wulandari for assisting with participants' recruitment and initial data collection, and Fatty Maulidira and Dwijaya Sari for their assistance.

\section{REFERENCES}

[1] Richards P., Stockill S., "Learning medicine: An informal guide to a career in medicine $16^{\text {th }}$ ed.," London: $B M J$ Pub Group, pp. 1-145, 2003.

[2] Reese SM., "Tired of being a doctor? choices for opting out of medicine. Medscape Business of Medicine, 2012," [Online]. Available: https://www.medscape.com/viewarticle/757765

[3] Syakurah, R. A., Prabandari, Y. S., Widyandana, D., et al., "Career choices, determinants, and need for medical career introduction among medical students," International Journal Research Medical Sciences., vol. 5, no. 5, pp. 1998-2002, 2017.

[4] Glynn RW, Kerin MJ., "Factors influencing medical students and junior doctors in choosing a career in surgery," The Surgeon, vol. 8, no. 4, pp. 187-91, 2010.

[5] Bland CJ, Meurer LN, Maldonado G., "Determinants of primary care specialty choice: a non-statistical metaanalysis of the literature," Academic Medicine, vol. 70, no. 7, pp. 620-41, 1995.

[6] Yamazaki, Y., Uka, T., Shimizu, H., et al., "Japanese medical students' interest in basic sciences: a questionnaire survey of a medical school in Japan," The Tohoku Journal of Experimental Medicine, vol. 229, no. 2, pp. 129-136, 2013.

[7] Soethout, M.B., Olle, J.T, Gerrit, V.D., "Development of an interest in a career in public health during medical school," Public Health, vol. 122, pp. 361-366, 2008.

[8] Bandura A., "Self-efficacy: The exercise of control," Macmillan, Feb 15, 1997.

[9] Betz NE., "Self-efficacy theory as a basis for career assessment," Journal of Career Assessment, vol. 8, no. 3, pp. 205-22, 2000.

[10] Lent RW, Brown SD, Hackett G., "Toward a unifying social cognitive theory of career and academic interest, choice, and performance," Journal of Vocational Behavior, vol. 45, no. 1, pp. 79-122, 1994.

[11] Nasta KA., "Influence of career self-efficacy beliefs on career exploration behaviour," Thesis, 2007.

[12] Betz NE, Borgen FH, Rottinghaus P., et al., "The expanded skills confidence inventory: Measuring basic dimensions of vocational activity," Journal of Vocational Behavior, vol. 62, no. 1, pp. 76-100, 2003.

[13] Betz NE, Voyten KK., "Efficacy and outcome expectations influence career exploration and decidedness," The Career Development Quarterly, vol. 46, no. 2, pp. 179-89, 1997.

[14] Ferry TR, Fouad NA, Smith PL., "The role of family context in a social cognitive model for career-related choice behavior: A math and science perspective," Journal of Vocational Behavior, vol. 57, no. 3, pp. 348-64, 2000.

[15] Ibrahim M., Fanshawe A., Patel V., et al., "What factors influence British medical students' career intentions?," Medical Teacher, vol. 36, no. 12, pp. 1064-72, 2014.

[16] Super DE., "A life-span, life-space approach to career development," Journal of Vocational Behavior, vol. 16, no. 3, pp. 282-98, 1980.

[17] Erikson EH., "Identity: Youth and crisis," WW Norton \& Company, 1994.

[18] Savickas ML., "Career adaptability: An integrative construct for life-span, life-space theory," The Career Development Quarterly, vol. 45, no. 3, pp. 247-59, 1997. 
[19] Heiligers PJ., "Gender differences in medical students' motives and career choice," BMC Medical Education, vol. 12, no. 1, p. 82, 2012.

[20] Querido SJ, Vergouw D., Wigersma L., et al., "Dynamics of career choice among students in undergraduate medical courses. A BEME systematic review: BEME Guide No. 33," Medical Teacher, vol. 38, no. 1, pp. 18-29, 2016.

[21] Lefevre JH, Roupret M., Kerneis S., Karila L., "Career choices of medical students: a national survey of 1780 students," Medical Education, vol. 44, no. 6, pp. 603-12, 2010.

[22] Correll SJ., "Gender and the career choice process: The role of biased self-assessments," American Journal of Sociology, vol. 106, no. 6, pp. 1691-730, 2001.

[23] Levine RB, Mechaber HF, Reddy ST, et al., "A good career choice for women': female medical students' mentoring experiences: a multi-institutional qualitative study," Academic Medicine, vol. 88, no. 4, pp. 527-34, 2013.

[24] Bickel J., "Gender equity in undergraduate medical education: a status report," Journal of Women's Health \& Gender-Based Medicine, vol. 10, no. 3, pp. 261-70, 2001.

[25] Sawitri DR, Creed PA, Zimmer-Gembeck MJ., "Parental influences and adolescent career behaviors in a collectivist cultural setting," International Journal for Educational and Vocational Guidance, vol. 14, no. 2, pp. $161-80,2014$.

[26] Bandura A., "Self-efficacy: toward a unifying theory of behavioral change," Psychological Review., vol. 84, no. 2, p. 191, 1977.

[27] Tang M., Smith PL., "Asian Americans' career choices: a path model to examine factors influencing their career choices," Journal of Vocational Behavior, vol. 54, pp. 142-157, 1999.

[28] Hofstede, G. Hofstede, GJ. Minkov M., "Cultures and Organizations: Software of the Mind, Revised and Expanded 3rd Edition," New York: McGraw-Hill, 2010.

[29] Sawitri DR, Creed PA., "Collectivism and perceived congruence with parents as antecedents to career aspirations: A social cognitive perspective," Journal of Career Development, vol. 44, no. 6, 2016, doi: $10.1177 / 0894845316668576$

[30] Abbott A., "The system of professions: An essay on the division of expert labor," University of Chicago Press, 7 February 2014.

[31] Taveira MD, Moreno ML., "Guidance theory and practice: The status of career exploration," British Journal of Guidance and Counselling, vol. 31, no. 2, pp. 189-208, 2003.

[32] Sullivan KR, Mahalik JR., "Increasing Career Self Efficacy for Women: Evaluating a Group Intervention,” Journal of Counseling \& Development, vol. 78, no. 1, pp. 54-62, 2000. 